\title{
Gestão da educação e do trabalho na saúde: enfrentando crises ou enfrentando o problema?
}

\author{
Management of healthcare education and work: dealing with crises or dealing with the problem?
}

¿ Gestión de la educación y del trabajo em salud: i enfrentamento de crisis o del problema?

O artigo de Mônica Carvalho e Maria Fátima de Sousa traz para o debate uma questão muito relevante, que pertence a uma agenda ainda não concluída nas políticas de saúde do Brasil: a gestão da educação e do trabalho na saúde e o modo como essa gestão se articula com as políticas de saúde. Esse é um tema que mobiliza diferentes perspectivas. Queremos abordá-lo sob a de política pública com o foco que as autoras propõem, ou seja, tomando o provimento e a fixação de profissionais como questão marcadora - e dialogar com a afirmação de que é necessário definir um "marco regulatório" para orientar as ações dos diferentes atores.

Inicialmente, é preciso considerar que as políticas de saúde induziram a ampliação da oferta de serviços de saúde no país. Considerando os dados da Pesquisa de Assistência Médico-Sanitária de 2009 (IBGE, 2010), verificamos um crescimento de $220 \%$ no número de estabelecimentos de saúde no período de 1988 a 2009, sendo que tal fenômeno é maior no setor público (o número de estabelecimentos mais que dobrou de 21,5 mil para 50,3 mil) do que na iniciativa privada (de 12,2 mil para 24,5 mil no mesmo período). Ainda entre 1988 e 2009, os dados mostram também uma pequena retração nos estabelecimentos de saúde com internação e um grande crescimento nos serviços de saúde sem internação (26,5 mil para 67,9 mil), tanto no segmento público (19,6 mil para 47,4 mil) quanto no privado (6,9 mil para 20,5 mil). Esse crescimento do número e da diversificação dos serviços produziu um incremento substancial no número de empregos em todo o país, aumentando de pouco mais de 575 mil, em 1980, para mais de 2 milhões de empregos em 2009 (IBGE, 2010). Esses dados não se referem ao setor de saúde como um todo, mas aos serviços assistenciais. Além da ampliação da rede, esses dados informam a mudança substancial do perfil do trabalho, efeito que está associado, em grande medida, à implantação de políticas de atenção básica, em particular, à Estratégia de Saúde da Família; portanto, com expectativa de reorganização de práticas. A questão que se coloca é: como essa mudança no perfil dos serviços foi absorvida pela formação dos trabalhadores?

O próprio artigo informa que essa mudança passou ao largo da formação e das diversas iniciativas pontuais feitas no período, tanto nos aspectos quantitativos quanto qualitativos. Sem alongarmos essa argumentação, basta o registro de que as tentativas de aproximação da gestão da educação e do trabalho não obtiveram

1,2 Bacharelado em Saúde Coletiva, Programa de Pós-Graduação em Saúde Coletiva, Universidade Federal do Rio Grande do Sul. Rua São Manoel, 963, Bairro Santa Cecília. Porto Alegre, RS, Brasil. 90620-110. ferlaalcindo@gmail.com 
êxito em articular as necessidades do sistema de saúde e as mudanças na formação. No caso em questão, observam-se mudanças nas ações e nos serviços e manutenção das lógicas formativas e da inserção dos profissionais de saúde nas práticas. Evidenciam-se, também, resistências às políticas para a superação do descompasso entre as transformações nas políticas de saúde e de gestão da educação e do trabalho. Aqui, parece importante recuperarmos não apenas as análises sobre as características do modelo biomédico e sua prioridade na assistência e no hospital, conforme fartamente descrito na literatura crítica às práticas vigentes (Ferla, 2007), mas, também, o conceito de instituições médicas (Luz, 1986), que descreve as racionalidades atuantes em organizações de saúde e de educação.

A autonomia entre políticas de saúde e educação e o predomínio de lógicas organizadas em torno do modelo de práticas vigentes têm parte de sua explicação associada à ação de instituições médicas, seja de âmbito corporativo, seja na reprodução do discurso hegemônico sobre a saúde. Parece-nos que um "marco regulatório" que pretenda capacidade institucional não deve negligenciar os efeitos de poder que essa rede de organizações e de discursos sobre a saúde tem sobre a formação e o trabalho. Ou seja, não basta apenas a aproximação entre os Ministérios da Educação e da Saúde para a formulação de políticas específicas, mas, também, a definição de uma orientação geral com base noutra lógica.

Mantendo o diálogo sobre a definição de um "marco regulatório", compartilhamos o diagnóstico de que iniciativas pontuais, como o PROVAB, terão apenas efeitos efêmeros, conforme demonstrado no estudo. O problema do provimento/da fixação de profissionais, sobretudo, médicos, é complexo, e não será resolvido pontualmente. As necessidades e características do trabalho no cotidiano demandam mais potência para a definição das mudanças. Também mais criatividade, o que nos faz lembrar a iniciativa dos Estágios e Vivências na Realidade do SUS (VER-SUS), retomado em 2011, e que já mobilizou estudantes e instituições, em diversas localidades do país, para o cotidiano do trabalho no SUS e a política de educação permanente.

O novo "marco regulatório", além de superar o modelo biomédico, precisa articular diferentes profissões e, sobretudo, constituir mecanismos efetivos de gestão com base no interesse público. A Constituição brasileira, na afirmação da cidadania, define a participação da população como diretriz do sistema de saúde, como marcadora do interesse público; e o Estado, como mediador dessa condição. A regulação corporativa, base do modelo atualmente vigente, teve início na primeira experiência da saúde como política pública por delegação e por conveniência do Estado. No sistema de saúde atual, fóruns híbridos de participação substituem a "especialização" na definição das bases para políticas. A superação da lógica corporativa deve incluir o reconhecimento desses espaços como fóruns de negociação do interesse público.

A resposta governamental às dificuldades de provimento e fixação não pode esquivar-se de colocar como desafio não apenas a distribuição de profissionais, objeto de iniciativas pontuais implementadas há anos, mas os avanços na qualidade da clínica, da gestão, da formação e da participação no SUS, sob pena de reiterarmos o erro de mobilizar soluções para crises sucessivas, e não para o problema, que é o divórcio entre a gestão da educação e a gestão do trabalho na saúde.

\section{Referências}

FERLA, A.A. Clínica em movimento. Caxias do Sul: Educs, 2007. IBGE. Instituto Brasileiro de Geografia e Estatística. Assistência Médico-Sanitária 2009. Rio de Janeiro: IBGE, 2010.

LUZ, M.T. As instituições médicas no Brasil: instituições e estratégias de hegemonia. 3.ed. Rio de Janeiro: Graal, 1986. 